\title{
Transatlantica
}

Revue d'études américaines. American Studies Journal

\section{Christine DESAFY-GRIGNARD. Arthur Miller : Une vie} à l'œuvre.

Paris : Michel Houdiard Editeur, 2003. 424 p. 26 euros.

\section{Trudy Bolter}

\section{(2) OpenEdition}

\section{Journals}

Édition électronique

URL : http://journals.openedition.org/transatlantica/1154

DOI : $10.4000 /$ transatlantica. 1154

ISSN : 1765-2766

Éditeur

AFEA

Référence électronique

Trudy Bolter, "Christine DESAFY-GRIGNARD. Arthur Miller : Une vie à l'œuvre. », Transatlantica [En ligne],

1 | 2003, mis en ligne le 16 novembre 2006, consulté le 29 avril 2021. URL : http://

journals.openedition.org/transatlantica/1154; DOI : https://doi.org/10.4000/transatlantica.1154

Ce document a été généré automatiquement le 29 avril 2021.

\section{c) (i) $\Theta$}

Transatlantica - Revue d'études américaines est mis à disposition selon les termes de la licence Creative Commons Attribution - Pas d'Utilisation Commerciale - Pas de Modification 4.0 International. 


\section{Christine DESAFY-GRIGNARD. Arthur Miller : Une vie à l'ouvre.}

Paris : Michel Houdiard Editeur, 2003. 424 p. 26 euros.

Trudy Bolter

\section{NOTE DE L'ÉDITEUR}

[Voir dans ce même numéro le droit de réponse de Christine Desafy-Grignard et la réponse de Trudy Bolter]

1 Dans ce livre, Christine Desafy-Grignard fait la navette entre l'autobiographie d'Arthur Miller, Timebends :A Life, (1987), et l'œuvre, qui inclut des pièces qui ont enregistré et marqué leur siècle, Death of a Salesman (1949) et The Crucible (1953). Faisant concorder les personnages des deux textes (la «vie » et l'ensemble des écrits), elle remet dans l'ordre chronologique les événements que Miller embrouille, les entrecoupant de retours en arrière, dans Timebends.

2 L'on a parfois l'impression de tenir entre les mains le premier jet mal corrigé d'un livre nécessaire (car peu d'ouvrages francophones sur Miller sont disponibles) mais inachevé. Il, est dommage que si peu de place soit accordée aux aspects théoriques du thème. Il est d'autant plus difficile d'excuser la profusion d'erreurs sur tous les plans: orthographe, histoire, histoire culturelle. ${ }^{1}$ Le traitement d'Odets (comme d'O'Neill et Williams) est tronqué, superficiel. ${ }^{2}$ Les notes (trop rares) lorsqu'elles sont présentes, sont souvent incomplètes. Quelques développements comme la discussion (134) du caractère tragique de Salesman sont rapides, dénués d'exemples, sans références, et n'apparaissent pas vraiment comme discours méticuleusement construit.

L'analyse manque parfois de rigueur. C'est grave, car Desafy-Grignard s'attache à montrer que Miller est auteur " juif », " juif psychologique » qui " trahit sa judéité » (379) par des intuitions se rapprochant de celles de Freud, davantage que « par le cadre de ses pièces»(379). Il s'agit même d'un « écrivain religieux ", « malgré son image de juif séculier » (381). 
Ce point de vue, qui se rapproche en partie de ceux d'Harold Bloom ou Ellen Schiff, qui le développent autrement, ${ }^{3}$ serait plus convaincant à mon avis s'il n'était pas affaibli par la présence de formulations essentialistes irréfléchies. Je cite comme exemple en le soulignant une maladresse regrettable parmi d'autres :

"Sa mère, Augusta, est ... plus superstitieuse (un trait de caractère chez les femmes juives que l'on retrouve chez plusieurs des héroïnes de l'œuvre) que pieuse, plus attirée par le côté occulte de sa religion que par l'orthodoxie du dogme » (17)

Utilisant sans nuance des termes éculés tels que la " yiddish mamma » $(22)^{5}$ pour décrire les personnages, l'auteur frôle parfois le stéréotype déplaisant (19, le juif « caméléon »). Recourir à ce type de raccourci me semble paresseux, voire dangereux . Malgré les lacunes et les analyses qui me paraissent contestables, Christine DesafyGrignard a eu la bonne idée de faire exister un livre sur un auteur majeur qui mérite de revenir à la mode. Elle traduit de l'anglais de grands extraits de l'œuvre millerienne et rend ainsi accessible à un plus large public les écrits d'un dramaturge qui associe poésie de la scène et conscience politique.

\section{NOTES}

1. Un exemple : «Constantin Stanislavski, ancien du Group Theater, mort en 1938. » (193).

2. Et notamment de sa pièce Awake and Sing (1935) traitant du caractère chimérique du rêve américain révélé dans le vécu d'une famille d'immigrés juifs, qui fait partie de l'intertexte évidente de Death of a Salesman, Il aurait été intéressant de traiter aussi la façon d'Odets d'être (et ne pas être) auteur « juif » peu de temps avant (et en même temps que) Miller.

3. Harold Bloom, ed., Arthur Miller, Coll. Bloom's BioCritiques, Broomall, Pa., Chelsea House, 2003 (5), et Ellen Schiff, ed., Awake and Singing : Seven Classic Plays from the American Jewish Repertoire, Harmondsworth, England, Penguin Mentor,1995, (xix).

4. Une question : où est le « dogme » du judaïsme ? religion sans « pape » mais aux mille commentateurs, la diversité étant tout aussi typique du judaïsme que du protestantisme américains. Mme. Miller, spirite, faisait tirer les cartes avant le départ de son fils pour l'université, activait avec délectation sa planchette Oul̈ja, communiquait avec l' « autre » monde, pratiques assez courantes àl'époque (années 20), à témoin le milieu du poète W.B. Yeats totalement différent mais obsédé par ces questions.

5. Personnage autoritaire présent, selon l'auteur, dans « toute la littérature juive américaine » (aucun titre n'est donné comme exemple précis). 
INDEX

Thèmes : Recensions

\section{AUTEUR}

TRUDY BOLTER

Institut d'Etudes Politiques, Université Montesquieu-Bordeaux IV 